\title{
AN EXPERIMENTAL STUDY OF HEAT PIPE HEAT EXCHANGER INSULATED WITH VACUUM CHAMBER UNDER NATURAL CONVECTION FOR BUTANOL AND METHANOL USED AS FUNCTIONING FLUID
}

\author{
SUMIT KUMAR RAI, ANJANEY PANDEY \& ALOK CHAUBE
}

Mechanical Engineering Department, M.G.C.G.V., Chitrakoot, Satna, Madhya Pradesh, India sumit.rai87@gmail.com¹, anjaneypandey_mgcgv@rediffmail.com², alokchaube@rediffmail.com³

\begin{abstract}
A methodical replica has been evolutes to resolve heat execution of HPHEVC under free convection cooling conditions by acquiring heat protection commence. The replica estimates the CCHT and RHT of the HPHEVC under free convection. The experimental results existed at $0^{\circ}, 15^{\circ}, 30^{\circ}, 45^{\circ}$ and $60^{\circ}$ tilt angles from vertical axis of HPHEVC at different - different inlet temperature of evaporator when methanol \& butanol is utilized as functioning fluids.The experimental setup has been invented in a manner such that the performance of the HPHEVC can be evaluated at separate tilt angles under free convection conditions. The innovative opinions disclose that inclination of pipe \& inlet temperature of evaporator influence the CCHT and RHT of the HPHEVC under natural convection.The tilt angle of heat pipe increases from $0^{\circ}$ to $15^{\circ}$ the heat transport rate decreases, and it starts increasing beyond $15^{\circ}$ tilt angle after that again start decreasing heat transport rate from $45^{\circ}$ to $60^{\circ}$ tilt angle for all the inlet temperature of evaporator. HPHE gives the good performance when butanol used as functioning fluid as compare to methanol.

KEYWORDS: Heat Pipe Heat Exchanger, Rate of Heat Transfer (RHT), Coefficient of Convective Heat Transfer $(\mathrm{CCHT})$
\end{abstract}

Received: Jun 10, 2020; Accepted: Jun 30, 2020; Published: Jul 22, 2020; Paper Id.: IJMPERDJUN2020422

\section{INTRODUCTION}

For manufacturing HPHE, the replica of individual HP is very important. The configuration of individual HP is decided based on several factors, such as the functioning temp range of HPHE, orientation of the evaporator with respect to the condenser\& the possibility of corrosion of the HP panel by the high or low temp fluid streams.

The literature review indicates that a good quantity of work has been accomplished on fundamental studies of HPs, which includes different types of transport limitations, choice of functioning fluid \& matter of construction of panel of HP \& heat resistances. These are critical parameters, which determine the execution of HP. For low temperature applications differ from $30{ }^{\circ} \mathrm{C}$ to $200{ }^{\circ} \mathrm{C}, \mathrm{Cu}$ water $\mathrm{HP} \&$ steel water $\mathrm{HP}$ has been extensively utilized, which may be because of its better thermal execution and cost effectiveness. The RHT of grooved HP is more towards $\mathrm{Cu}$ water wicked $\mathrm{HP}$, which may be due to less resistance in condensate return and uniform distribution of functioning fluid in grooves, but its manufacturing procedure is relatively more complicated.

The heat execution of a HP is determined by its heating resistance. The literature review has been reported that interior heating resistance of a HP is low but heating resistances at exterior surface of evap. \& cond. are high, 
which limit the RHT. In many cases, it may be approximately equal to the overall heating resistance of HP. The external heating resistance at condenser reduces as functioning temp at condenser increases or by increasing the velocity of cooling fluid. The heating resistance at condenser under free convection is high towards other heating resistances. In free convection, fins are utilized to enhance thermal transmission surface \& in turn augment RHT. The pitch of fins is usually around 6 to $8 \mathrm{~mm}$ in event of free convection, whereas 2 to $3 \mathrm{~mm}$ in event of unnatural convection. If fins aren't utilized than span of the HP should be increases with respect to radii of pipe in event of free convection.

This segment presents a survey of exploration effort carried out in the area of fundamental studies on HP and its applications, general empirical correlations under forced \& natural convection, modelling of HPHE, experimental studies, and applications of HPHE. This survey has been carried out with the following objective:

- To identify some of the important design aspects of HPHEs.

- To identify the correlations for heat transfer and this can be utilized in current investigation.

- To identify circumstances for natural convection.

- To identify the effects and nature of different - different fluids under natural convection in HPHEVC.

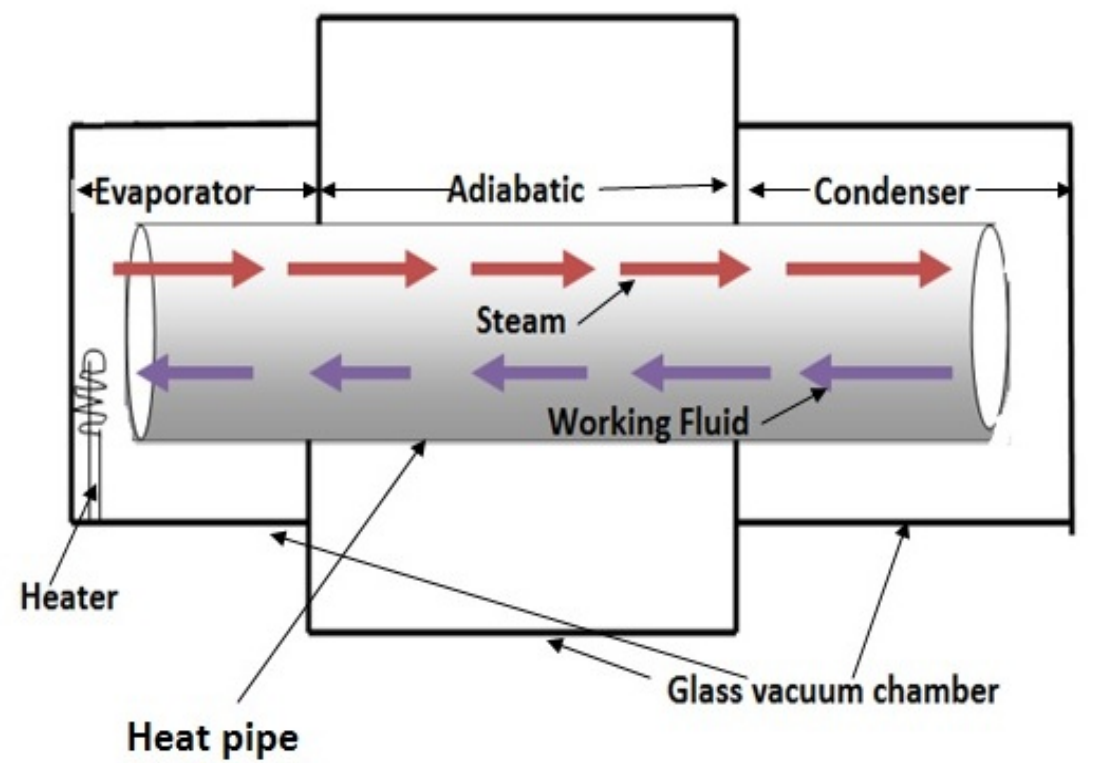

Figure 1: HPHE insulated with glass vacuum chamber

The heat execution of a HP is determined by its heating resistance. The literature review has been reported that interior heating resistance of a HP is low but heating resistances at exterior surface of evap. \& cond. are high, which limit the RHT. In many cases, it may be approximately equal to the overall heating resistance of HP. The external heating resistance at condenser reduces as functioning temp at condenser increases or by increasing the velocity of cooling fluid. The heating resistance at condenser under free convection is high towards other heating resistances. In free convection, fins are utilized to enhance thermal transmission surface \& in turn augment RHT. The pitch of fins is usually around 6 to $8 \mathrm{~mm}$ in event of free convection, whereas 2 to $3 \mathrm{~mm}$ in event of unnatural convection. If fins aren't utilized than span of the HP should be increases with respect to radii of pipe in event of free convection. 


\section{SELECTION OF FUNCTIONING FLUID}

The functioning fluid chose on the basis of price, accessibility, agreement with container materials, and using vapour temperature variety. The other reflection for selection of functioning fluid are best heating strength, quickly converts liquid into vapour, viscosities must be low and vapour pressure according to the working temperature variety. In this experiment butanol and methanol used as functioning fluid. Table 1 represents the thermo physical properties of butanol and methanol.

\subsection{Properties of Acetone or Butanol}

Acetone or Butanol or propanone is an organic compound. It is the simplest and smallest ketone. It is produced directly or indirectly from propylene. The other process to produced Acetone or Butanol is dry distillation of calcium acetate. The chemical reaction is

$\mathrm{Ca}\left(\mathrm{CH}_{3} \mathrm{COO}\right)_{2} \rightarrow \mathrm{CaO}_{(\mathrm{S})}+\mathrm{CO}_{2(\mathrm{G})}+\left(\mathrm{CH}_{3}\right)_{2} \mathrm{CO}(\mathrm{V})$

(1) Physical properties of Acetone or Butanol are as follows.

1. Molecular Formula $-\mathrm{C}_{3} \mathrm{H}_{6} \mathrm{O}$

2. Gas Number - $\quad$ 67-64-1

3. Boiling point $-56^{\circ} \mathrm{C}$

4. Melting point $\quad--94^{0} \mathrm{C}$

5. Flash point $--17.2^{0} \mathrm{C}$

6. Viscosity $\quad-0.306$ at $25^{\circ} \mathrm{C}$

\subsection{Properties of Methanol}

The other name is methyl alcohol. Methanol is a polar solvent, explosive, colorless and flammable liquid. It is closed to that drinking alcohol like ethanol. The destructive distillation of wood is being produced methanol. Acetic acid can be produced from methanol.

$2 \mathrm{CH}_{3} \mathrm{OH}+\mathrm{O}_{2} \rightarrow 2 \mathrm{CH}_{2} \mathrm{O}+2 \mathrm{H}_{2} \mathrm{O}$

(1) Physical properties of Methanol are as follows.

1. Molecular Formula $-\mathrm{CH}_{3} \mathrm{OH}$

2. Molecular Weight $\quad-32.04 \mathrm{~g} / \mathrm{mol}$

3. Gas Number - 67-56-1

4. Evaporating point $\quad-64.5^{\circ} \mathrm{C}$

5. Liquefy point $\quad--98^{\circ} \mathrm{C}$

6. Flash point $\quad-11.1^{0} \mathrm{C}$

7. Viscosity -0.544 at $25^{\circ} \mathrm{C}$ 
Table 1: Properties of butanol and methanol in S.I. Units

\begin{tabular}{|c|c|c|c|c|c|c|c|c|c|c|c|}
\hline \multirow[t]{2}{*}{$\begin{array}{l}\text { S. } \\
\text { No. }\end{array}$} & \multirow[t]{2}{*}{$\begin{array}{c}\text { Temperature } \\
\left({ }^{\circ} \mathrm{C}\right)\end{array}$} & \multicolumn{2}{|c|}{$\begin{array}{l}\text { Density } \\
\rho\left(\mathrm{kg} / \mathrm{m}^{3}\right)\end{array}$} & \multicolumn{2}{|c|}{$\begin{array}{l}\text { Specific heat } \\
\text { Cp }(J / k g k)\end{array}$} & \multicolumn{2}{|c|}{$\begin{array}{c}\text { Dynamic viscosity } \\
\mu(\text { Pa.sec.) }\end{array}$} & \multicolumn{2}{|c|}{$\begin{array}{l}\text { Thermal } \\
\text { conductivity } \\
\mathbf{K}(\mathbf{W} / \mathbf{m k})\end{array}$} & \multicolumn{2}{|c|}{$\begin{array}{c}\text { Kinematic viscosity } v \\
\left(\mathrm{M}^{2} / \mathrm{sec}\right)\end{array}$} \\
\hline & & Butanol & Methanol & Butanol & Methanol & Butanol & Methanol & Butanol & Methanol & Butanol & Methanol \\
\hline 1 & 40 & 794 & 775 & 2480 & 2633 & 0.00018 & 0.000447 & 0.1644 & 0.196 & $2.26 \mathrm{E}-07$ & $5.76 \mathrm{E}-07$ \\
\hline 2 & 43 & 792 & 773 & 2493 & 2651 & 0.00017 & 0.000435 & 0.1641 & 0.195 & $2.14 \mathrm{E}-07$ & $5.62 \mathrm{E}-07$ \\
\hline 3 & 46 & 788 & 767 & 2520 & 2687 & 0.00015 & 0.000410 & 0.1635 & 0.194 & 1.90E-07 & 5.34E-07 \\
\hline 4 & 49 & 786 & 765 & 2534 & 2706 & 0.00014 & 0.000399 & 0.1632 & 0.193 & $1.78 \mathrm{E}-07$ & $5.21 \mathrm{E}-07$ \\
\hline 5 & 52 & 784 & 763 & 2547 & 2726 & 0.00013 & 0.000389 & 0.1629 & 0.193 & $1.65 \mathrm{E}-07$ & $5.09 \mathrm{E}-07$ \\
\hline 6 & 55 & 782 & 760 & 2561 & 2745 & 0.00012 & 0.000379 & 0.1627 & 0.192 & $1.53 \mathrm{E}-07$ & $4.98 \mathrm{E}-07$ \\
\hline 7 & 58 & 780 & 758 & 2575 & 2765 & 0.00012 & 0.000368 & 0.1624 & 0.192 & $1.47 \mathrm{E}-07$ & $4.87 \mathrm{E}-07$ \\
\hline 8 & 61 & 778 & 755 & 2589 & 2785 & 0.00011 & 0.000360 & 0.1622 & 0.190 & $1.41 \mathrm{E}-07$ & 4.76E-07 \\
\hline
\end{tabular}

\section{SELECTION OF CONTAINER}

The selection of container has been agreement with functioning fluid, high heating execution, case of fabrication, and strength to weight ratio. Literature indicates that stainless steel is compatible with methanol and Acetone or Butanol. Stainless steel has good thermal conductance property as well as cost advantage including the case of fabrication; therefore, we use cylindrical stainless steel pipe as HP container.

HPs can be made of different cross-sectional shapes. The circular cross sections are most common configuration and can withstand high stresses. A stainless steel pipe with $0.07 \mathrm{~m}$ and $0.05 \mathrm{~m}$ of outer and inner radius respectively having length of $0.50 \mathrm{~m}$ is to be selected for manufacturing of setup. The $0.10 \mathrm{~m}$ length has been selected from $0.50 \mathrm{~m}$ length of HP as evap. section to maintain the aspect ratio $\left(\mathrm{L}_{\mathrm{e}} / \mathrm{d}_{\mathrm{i}}\right)$ greater than equal to 10 as suggested by literature review. The adiabatic \& condenser lengths are kept as $0.3 \mathrm{~m} \& 0.1 \mathrm{~m}$, respectively. A circular stainless steel HP is fitted inside the vacuum box. Glass has good thermal conductance property as well as cost advantage including the case of fabrication; therefore, make the vacuum container by rectangular pieces of glass. A glass box having length ${ }^{\times}$width ${ }^{\times}$height is to cover adiabatic section is $0.2^{\times} 0.2^{\times} 0.3$ in m respectively and two glass box having length ${ }^{\times}$width ${ }^{\times}$height is to cover evap. and condenser section is $0.1 \times 0.1 \times 0.1$ in m respectively. The Vacuum is generated inside the glass boxes act as insulating material for HP. Fig.2 show the experimental setup of HPHEVC.

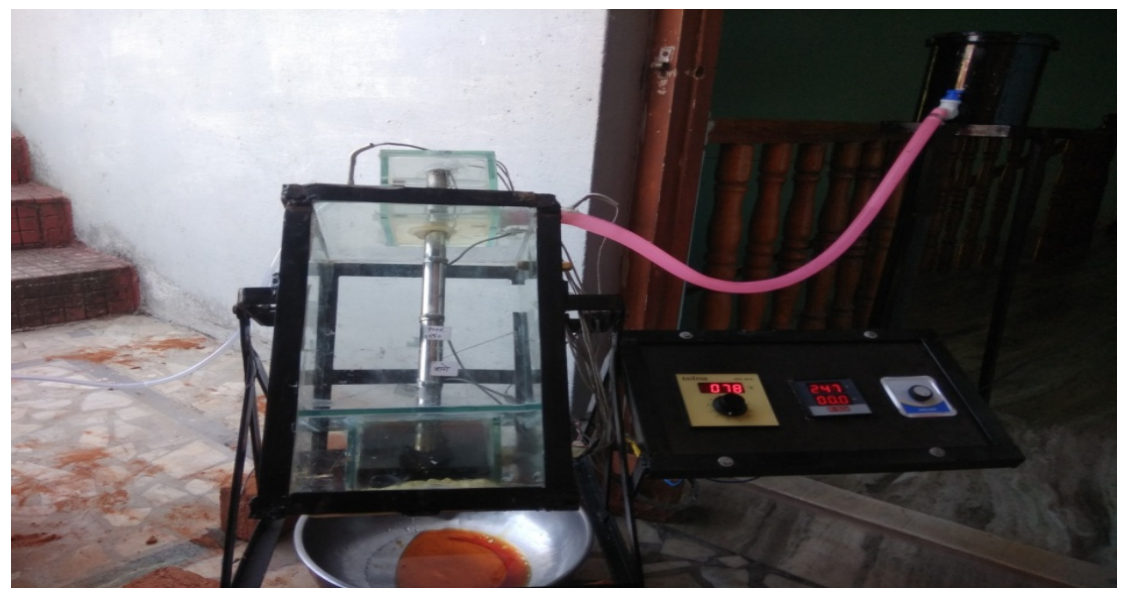

Figure 2: Test rig of HPHEVC 


\section{MATHEMATICAL FORMULATION}

To determine the CCHT and RHT, the HPHEVC has been modelled as a thermal resistance network. The CCHT and RHT have been computed on the internal surface of evaporator. The methodology adopted for calculation of CCHT and RHT across the HPHEVC under natural convection is described below:

\section{For CCHT of a heat pipe}

The natural convection heat transfer from inclined tube from y axis computed by the correlations of

$\mathrm{Nu}=\mathrm{C}^{\times}\left(\mathrm{Gr}^{\times} \operatorname{Pr}^{\times} \cos \theta\right)^{\mathrm{n}}$

Here $\theta$ is slope of HP of HP from vertical axis or y axis.

\section{Grashoff number (Gr)}

$\mathrm{Gr}=\frac{\left(\mathrm{L} 1^{3} \cdot \cdot \cdot \mathrm{g} \cdot \Delta \mathrm{T}\right)}{\mathrm{v}^{2}}$

Where,

- Lengths of evap. (L1), $\mathrm{m}=0.1 \mathrm{~m}$

- Gravitational Acceleration (g), $\mathrm{m} / \mathrm{sec}^{2}=9.81 \mathrm{~m} / \mathrm{sec}^{2}$

- Kinematic viscosity $(v), \mathrm{M}^{2} / \mathrm{sec}=$ depends upon inlet temperature of the evap. and functioning fluids.

- Co-efficient of volumetric expansion $(\beta),{ }^{0} \mathrm{C}^{-1}$

- Mean film temperature $(\Delta \mathrm{T}),{ }^{0} \mathrm{C}$

Prandtl number (Pr)

$\operatorname{Pr}=\frac{\mu * C p}{K}$

Where,

- Dynamic viscosity $(\mu)$, Pascal.sec.

- Specific heat $(\mathrm{Cp})$, Joule/ $\mathrm{kg}-{ }^{0} \mathrm{C}$

- Thermal conductivity $(\mathrm{K}) \mathrm{W} /\left(\mathrm{m}-{ }^{0} \mathrm{C}\right)$

The Nusselt number of heating fluid is to be computed by correlations available in the table 2 who is given by G.F.C. Rogeks and Y. R. Mayhew in Text book of Engineering Thermodynamics.

Table 2: Simplified equations for natural convection CCHT at atmospheric pressure

\begin{tabular}{|c|c|c|c|}
\hline \multirow{2}{*}{$\begin{array}{l}\text { S. } \\
\text { No. }\end{array}$} & \multirow[t]{2}{*}{ Descriptions } & \multicolumn{2}{|c|}{$\begin{array}{c}\text { For Calculate CCHT IN W/m } \mathrm{m}^{20} \mathrm{C} \text { with the help of NUSSELT } \\
\text { number }\end{array}$} \\
\hline & & Laminar or Transition & Turbulent \\
\hline 1 & $\begin{array}{l}\text { Vertical or inclined with y axis plate, or } \\
\text { cylinder having diameter and height }\end{array}$ & $\begin{array}{l}\mathbf{N u}=\mathbf{0 . 5 9} *(\mathbf{G r} \cdot \operatorname{Pr} \cdot \cos \boldsymbol{\theta})^{\mathbf{0 . 2 5}}, \\
\text { for } \\
10^{4}<(\text { Gr.Pr. } \cos \theta)<10^{9}\end{array}$ & $\begin{array}{l}\mathbf{N u}=\mathbf{0 . 5 9} *(\mathbf{G r} \cdot \operatorname{Pr} \cdot \cos \boldsymbol{\theta})^{\mathbf{1 / 3}}, \\
\text { for } \\
10^{9}<(\text { Gr.Pr. } \cos \theta)<10^{12}\end{array}$ \\
\hline 2 & Horizontal cylinder of diameter $\mathrm{d}$ & $\mathrm{Nu}=0.6^{*}(\mathrm{Gr} \cdot \operatorname{Pr} \cdot \cos \theta)^{0.25}$ & $\mathrm{Nu}=0.6^{*}(\mathrm{Gr} \cdot \operatorname{Pr} \cdot \cos \theta)^{1 / 3}$ \\
\hline
\end{tabular}




\begin{tabular}{|c|c|c|c|}
\hline & & $\begin{array}{l}\text { for } \\
10^{4}<(\text { Gr.Pr. } \cos \theta)<10^{9}\end{array}$ & $\begin{array}{l}\text { for } \\
10^{9}<(\text { Gr.Pr. } \cos \theta)<10^{12}\end{array}$ \\
\hline $\mathbf{3}$ & $\begin{array}{l}\text { Square plate }(1 * 1) \text { : Heated plate facing up, } \\
\text { or Cooled plate facing down }\end{array}$ & $\begin{array}{l}\mathbf{N u}=\mathbf{0 . 5 9} *(\mathbf{G r} \cdot \operatorname{Pr} \cdot \cos \boldsymbol{\theta})^{\mathbf{0 . 2 5}}, \\
\text { for } \\
10^{5}<(\mathrm{Gr} \cdot \operatorname{Pr} \cdot \cos \theta)<2 * 10^{7}\end{array}$ & $\begin{array}{l}\text { Nu }=\mathbf{0 . 5 9} *(\text { Gr.Pr. } \cos \theta)^{\mathbf{1} / 3}, \\
\text { for } \\
2 * 10^{7}<(\text { Gr.Pr. } \cos \theta)<3 * 10^{10}\end{array}$ \\
\hline 4 & $\begin{array}{l}\text { Square plate }(1 * 1) \text { : Cooled plate facing up, } \\
\text { or Heated plate facing down }\end{array}$ & $\begin{array}{l}\text { Nu }==\mathbf{0 . 5 9} *(\text { Gr.Pr. } \cos \boldsymbol{\theta})^{\mathbf{0 . 2 5}} \\
\text { For } \\
3 * 10^{5}<(\text { Gr.Pr. } \cos \theta)<3 * 10^{10}\end{array}$ & \\
\hline
\end{tabular}

The value of CCHT (h), $\mathrm{W} / \mathrm{m}^{2}-{ }^{0} \mathrm{C}$

$\mathrm{Nu}=\frac{(\mathrm{h} . \mathrm{L})}{\mathrm{K}}$

Where,

- $\mathrm{h}_{\text {or }} \mathrm{h}_{\text {theoretical }}=$ Theoretical value of CCHT, $\mathrm{W} / \mathrm{m}^{2}-{ }^{0} \mathrm{C}$

- $\mathrm{L}=$ Span of HP in $\mathrm{m}=0.5$ meter

- $\mathrm{K}=$ Thermal conductivity in $\left(\mathrm{Watt} / \mathrm{m}{ }^{0} \mathrm{C}\right)$

\section{For Heat Input to the Evaporator in W}

$\mathrm{qe}=\frac{\mathrm{m} \cdot \mathrm{cp} \cdot \Delta \mathrm{t}}{\text { time }}$

$\mathrm{qe}=\frac{\rho . \text { volume.cp. } . \Delta \mathrm{t}}{\text { time }}$

$\mathrm{qe}=\frac{\rho \cdot \text { volume.cp. }\left\{\left[\frac{\mathrm{Te} 1+\mathrm{Te} 2}{2}\right]-\mathrm{Tatm}\right\}}{\text { time }}$

Where,

- $\rho=$ Density

- $\quad \mathrm{Cp}=$ Specific heat

- Volume $=$ Volume of box who filled with functioning fluids, $\mathrm{m}^{3}=10^{\times} 10^{\times} \times 10^{-6} \mathrm{~m}^{3}$

- $\quad\left(\mathrm{T}_{\text {atm }}\right.$ or $\left.\mathrm{T}_{10}\right)=$ Ambient temperature, ${ }^{0} \mathrm{C}$

- $\quad\left(\mathrm{Te}_{1}\right.$ and $\left.\mathrm{Te}_{2}\right)=$ Evap. temperature, ${ }^{0} \mathrm{C}$

- Time in second,

These characteristic are utilized to compute the practical estimate of CCHT and RHT. The variable parameters for evaluations are Inlet temperature of evaporator (like 40, 43, 46, 49, 52, 55, 58 and $61^{\circ} \mathrm{C}$ ), Tilt angle of HP from vertical position (like $0^{0}, 15^{\circ}, 30^{\circ}, 45^{\circ}$ and $60^{\circ}$ ), and the different - different functioning Fluids is utilized (like Methanol and Butanol). The thermal properties of all the fluids plays very important role for natural convection conditions. The thermal properties are also varies at variable input temperature range of evaporator. 


\section{RESULTS \& DELIBERATIONS}

The experimental study shows the thermal performance of HPHEVC under natural convection condition when butanol and methanol used as functioning fluid. The tables and graphs show the results at verities of input temperature of evaporator, tilting angles of HP from vertical axis and different - different functioning fluids.

\subsection{CCHT}

The practical values of CCHT has been calculated when butanol and methanol is utilized as functioning fluids. It is noted that CCHT increases as rising of inlet temperature for all arrangements of HP like HP tilt at an angle of $0^{\circ}, 15^{\circ}, 30^{\circ}, 45^{\circ}$ and $60^{\circ}$ from vertical axis.

The table 3 and table 4 are showing the experimentally measured and calculated values of CCHT of HPHEVC under natural convection. The tables show the results at verities of input temperature of evaporator, tilting angles of HP from vertical axis when butanol and methanol utilized as functioning fluids.

Table 3: The value of CCHT when butanol is utilize as functioning fluid

\begin{tabular}{|c|c|c|c|c|c|c|}
\hline \multirow{2}{*}{$\begin{array}{c}\text { S. } \\
\text { No. }\end{array}$} & $\begin{array}{c}\text { Angle of } \\
\text { inclination }\end{array}$ & $\mathbf{0}$ & $\mathbf{1 5}$ & $\mathbf{3 0}$ & $\mathbf{4 5}$ & $\mathbf{6 0}$ \\
\cline { 2 - 7 } & Temperature & $\mathbf{h}_{\text {PRACTICAL }}$ & $\mathbf{h}_{\text {PRACTICAL }}$ & $\mathbf{h}_{\text {PRACTICAL }}$ & $\mathbf{h}_{\text {PRACTICAL }}$ & $\mathbf{h}_{\text {PRACTICAL }}$ \\
\hline 1 & 40 & 561.78 & 557.81 & 530.87 & 495.66 & 439.90 \\
\hline 2 & 43 & 606.43 & 611.48 & 579.17 & 539.02 & 485.28 \\
\hline 3 & 46 & 661.44 & 651.19 & 635.36 & 594.38 & 527.65 \\
\hline 4 & 49 & 706.23 & 700.97 & 672.71 & 634.10 & 553.32 \\
\hline 5 & 52 & 746.02 & 747.36 & 710.76 & 675.25 & 592.19 \\
\hline 6 & 55 & 802.72 & 784.80 & 755.93 & 705.35 & 632.79 \\
\hline 7 & 58 & 837.12 & 825.53 & 809.01 & 745.28 & 663.21 \\
\hline 8 & 61 & 869.11 & 874.32 & 836.73 & 774.95 & 707.37 \\
\hline
\end{tabular}

Table 4: The value of CCHT when methanol is utilize as functioning fluid

\begin{tabular}{|c|c|c|c|c|c|c|}
\hline \multirow{2}{*}{$\begin{array}{c}\text { S. } \\
\text { No. }\end{array}$} & $\begin{array}{c}\text { Angle of } \\
\text { inclination }\end{array}$ & $\mathbf{0}$ & $\mathbf{1 5}$ & $\mathbf{3 0}$ & $\mathbf{4 5}$ & $\mathbf{6 0}$ \\
\cline { 2 - 7 } & Temperature & $\mathbf{h}_{\text {PRACTICAL }}$ & $\mathbf{h}_{\text {PRACTICAL }}$ & $\mathbf{h}_{\text {PRACTICAL }}$ & $\mathbf{h}_{\text {PRACTICAL }}$ & $\mathbf{h}_{\text {PRACTICAL }}$ \\
\hline 1 & 40 & 467.95 & 465.18 & 441.45 & 419.21 & 367.10 \\
\hline 2 & 43 & 509.06 & 507.50 & 486.92 & 452.62 & 397.42 \\
\hline 3 & 46 & 541.24 & 529.89 & 497.45 & 469.53 & 434.12 \\
\hline 4 & 49 & 552.30 & 545.95 & 534.08 & 495.99 & 449.95 \\
\hline 5 & 52 & 580.99 & 572.45 & 551.05 & 521.79 & 471.68 \\
\hline 6 & 55 & 600.54 & 598.17 & 582.96 & 540.17 & 486.92 \\
\hline 7 & 58 & 643.44 & 628.93 & 595.58 & 564.77 & 512.02 \\
\hline 8 & 61 & 649.71 & 654.00 & 640.65 & 587.32 & 516.34 \\
\hline
\end{tabular}

Fig. 3 to fig. 7 reveals the Practical outcomes of CCHT decreases as rising of angle of inclination of HP from vertical axis for methanol \& butanol is utilized as functioning fluids at different - different inlet temperature of evaporator. 


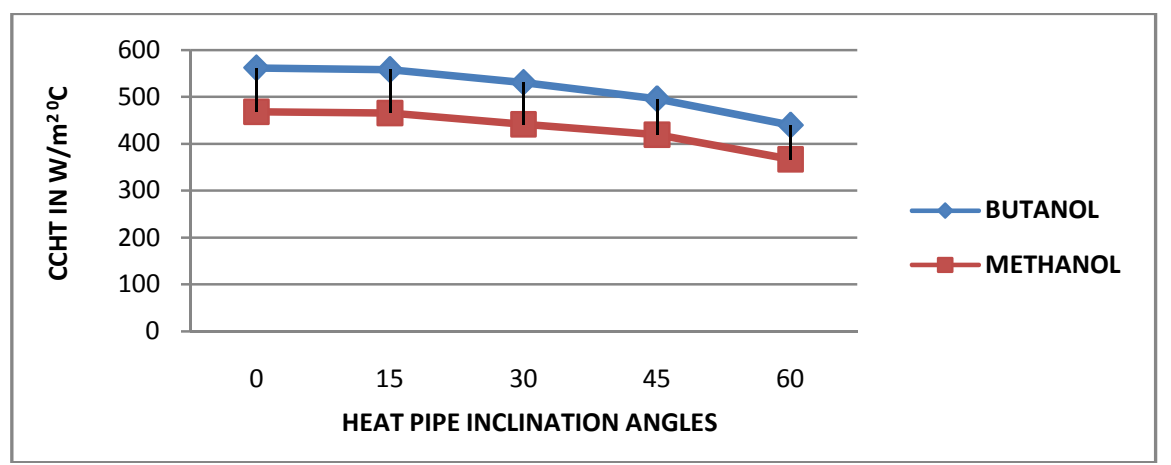

Figure 3: The practically calculated value of CCHT for $40{ }^{\circ} \mathrm{C}$ inlet temperature

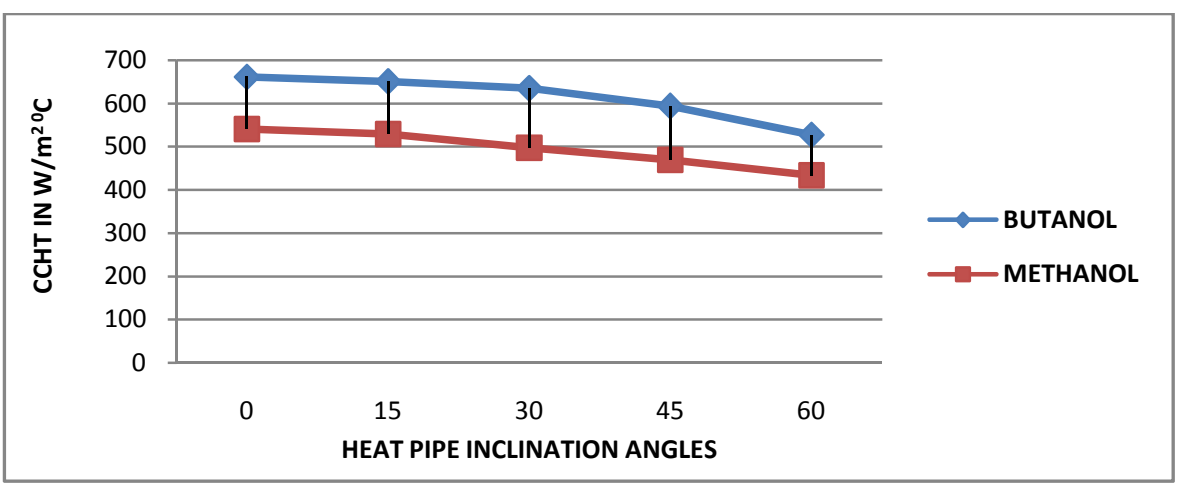

Figure 4: The practically calculated value of CCHT for $46^{\circ} \mathrm{C}$ inlet temperature

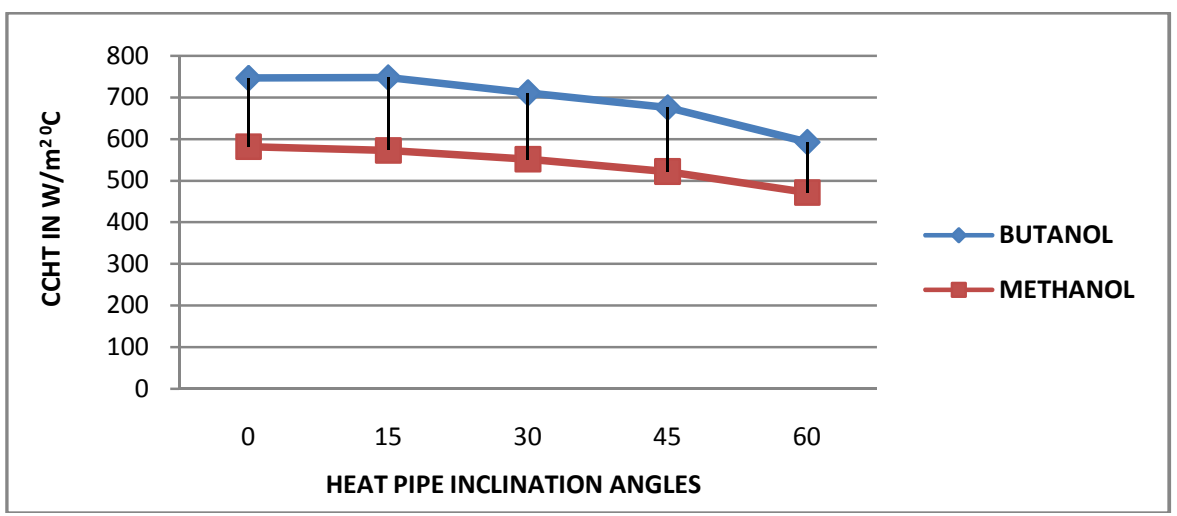

Figure 5: The practically calculated value of CCHT for $52^{\circ} \mathrm{C}$ inlet temperature

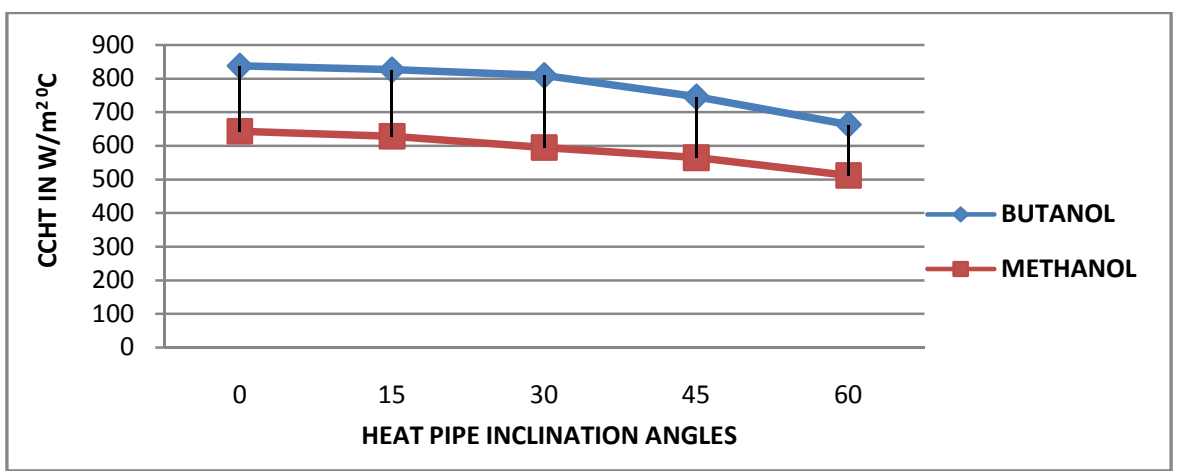

Figure 6: The practically calculated value of CCHT for $58{ }^{\circ} \mathrm{C}$ inlet temperature 


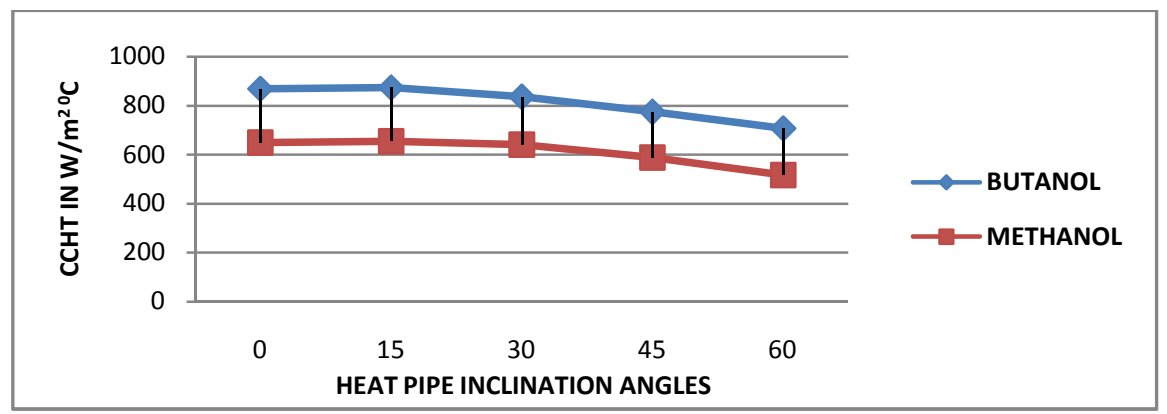

Figure 7: The practically calculated value of $\mathrm{CCHT}$ for $61^{\circ} \mathrm{C}$ inlet temperature

\subsection{RHT}

The RHT of the HPHEVC at various functioning fluids \& inlet temperatures as well as inclination of HP is presented in this portion. The effects of heating fluids in the evap. section on the RHT of the HPHEVC have also been shown in graphical plots from Figures. It is noted that at particular heating fluids e.g. methanol \& butanol, the RHT of HPHEVC increases slightly with increasing inlet temperature in evaporator section, since condenser temperature quit grow remarkably.

The table 5 and table 6 are showing the experimentally measured and calculated values of HPHEVC under natural convection. The tables show the results at verities of input temperature of evaporator, tilt angles of HP from vertical position when butanol and methanol used as functioning fluid.

Table 5: The value of RHT when butanol is utilize as functioning fluid

\begin{tabular}{|c|c|c|c|c|c|c|}
\hline \multirow{2}{*}{$\begin{array}{c}\text { S. } \\
\text { No. }\end{array}$} & $\begin{array}{c}\text { Angle of } \\
\text { inclination }\end{array}$ & $\mathbf{0}$ & $\mathbf{1 5}$ & $\mathbf{3 0}$ & $\mathbf{4 5}$ & $\mathbf{6 0}$ \\
\cline { 2 - 7 } & Temperature & $\mathbf{Q}_{\text {PRACTICAL }}$ & $\mathbf{Q}_{\text {PRACTICAL }}$ & $\mathbf{Q}_{\text {PRACTICAL }}$ & $\mathbf{Q}_{\text {PRACTICAL }}$ & $\mathbf{Q}_{\text {PRACTICAL }}$ \\
\hline 1 & 40 & 100.08 & 93.66 & 90.28 & 89.79 & 79.14 \\
\hline 2 & 43 & 121.17 & 106.69 & 105.98 & 103.08 & 92.74 \\
\hline 3 & 46 & 143.10 & 128.58 & 133.08 & 132.92 & 122.27 \\
\hline 4 & 49 & 186.16 & 155.65 & 155.92 & 157.97 & 147.60 \\
\hline 5 & 52 & 227.08 & 187.14 & 181.76 & 186.00 & 172.36 \\
\hline 6 & 55 & 244.16 & 201.44 & 214.28 & 219.03 & 201.45 \\
\hline 7 & 58 & 274.39 & 242.83 & 238.46 & 246.08 & 228.47 \\
\hline 8 & 61 & 324.00 & 283.73 & 275.81 & 272.51 & 263.18 \\
\hline
\end{tabular}

Table 6: The value of RHT when methanol is utilize as functioning fluid

\begin{tabular}{|c|c|c|c|c|c|c|}
\hline \multirow{2}{*}{$\begin{array}{c}\text { S. } \\
\text { No. }\end{array}$} & $\begin{array}{c}\text { Angle of } \\
\text { inclination }\end{array}$ & $\mathbf{0}$ & $\mathbf{1 5}$ & $\mathbf{3 0}$ & $\mathbf{4 5}$ & $\mathbf{6 0}$ \\
\cline { 2 - 7 } & Temperature & $\mathbf{Q}_{\text {PRACTICAL }}$ & $\mathbf{Q}_{\text {PRACTICAL }}$ & $\mathbf{Q}_{\text {PRACTICAL }}$ & $\mathbf{Q}_{\text {PRACTICAL }}$ & $\mathbf{Q}_{\text {PRACTICAL }}$ \\
\hline 1 & 40 & 86.62 & 73.30 & 67.63 & 64.02 & 50.77 \\
\hline 2 & 43 & 92.41 & 87.12 & 85.58 & 85.47 & 65.08 \\
\hline 3 & 46 & 114.05 & 108.06 & 97.24 & 93.57 & 87.58 \\
\hline 4 & 49 & 130.61 & 118.04 & 117.13 & 114.16 & 98.16 \\
\hline 5 & 52 & 154.57 & 140.38 & 142.48 & 140.06 & 115.63 \\
\hline 6 & 55 & 173.21 & 163.87 & 166.23 & 167.34 & 129.28 \\
\hline 7 & 58 & 191.77 & 186.65 & 192.94 & 199.36 & 158.29 \\
\hline 8 & 61 & 230.31 & 227.95 & 225.93 & 229.10 & 167.78 \\
\hline
\end{tabular}


This study reveals the graph of practical values of RHT with respect to the inlet temperature of evaporator and tilting angles of HP from vertical axis for methanol \& butanol is utilized as functioning fluids. Fig. 8 to fig. 12 reveals the results of RHT for different - different functioning fluids is utilized in a same inlet temperature of evaporator at different tilt angle of HPHEVC from vertical.

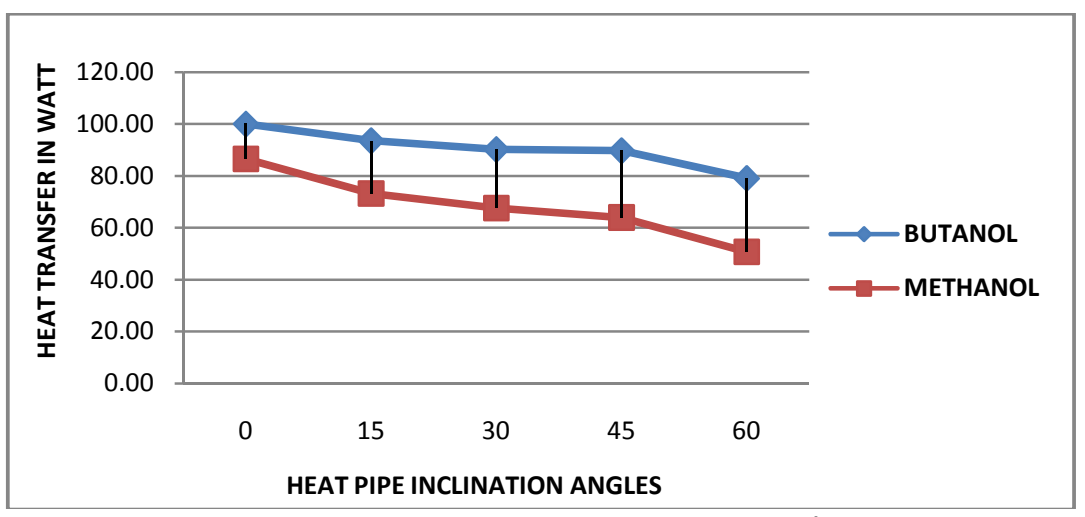

Figure 8: The practically calculated value of RHT for $40^{\circ} \mathrm{C}$ inlet temperature

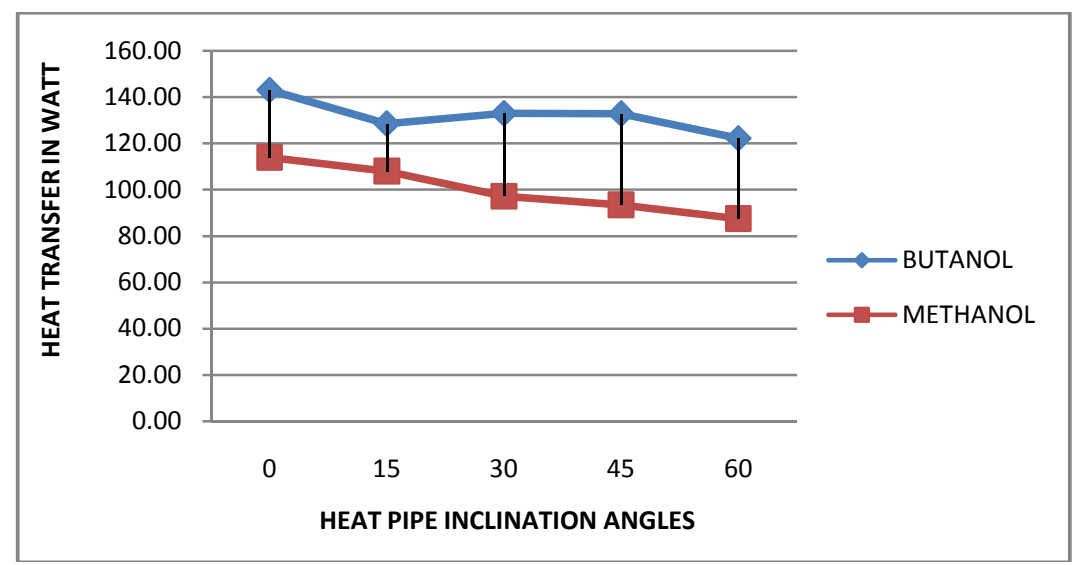

Figure 9: The practically calculated value of RHT for $46{ }^{\circ} \mathrm{C}$ inlet temperature

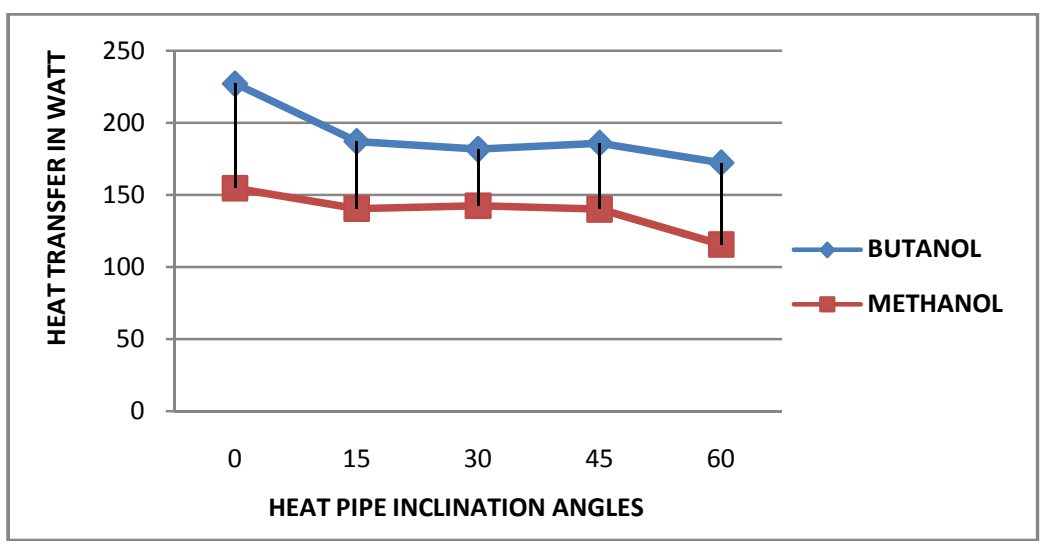

Figure 10: The practically calculated value of RHT for $52{ }^{\circ} \mathrm{C}$ inlet temperature 


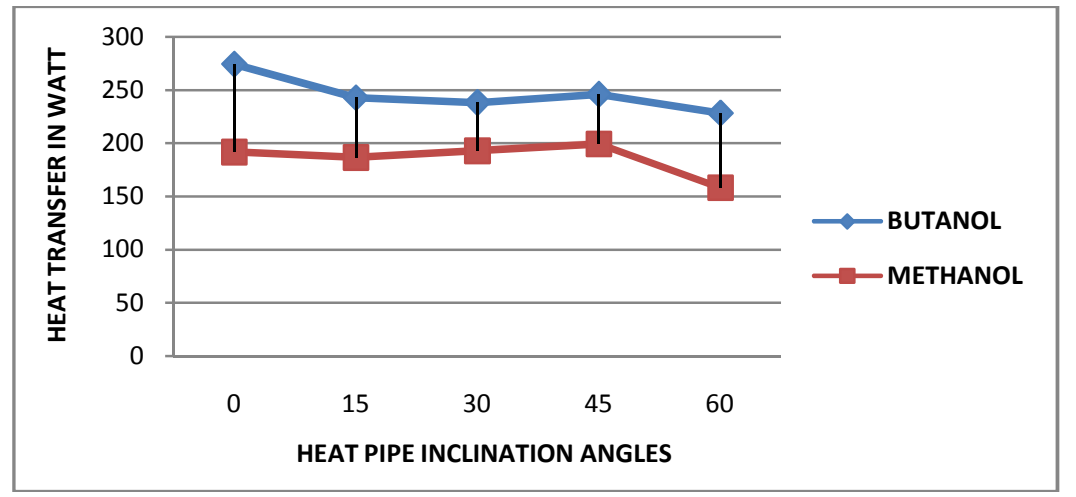

Figure 11: The practically calculated value of RHT for $58{ }^{\circ} \mathrm{C}$ inlet temperature

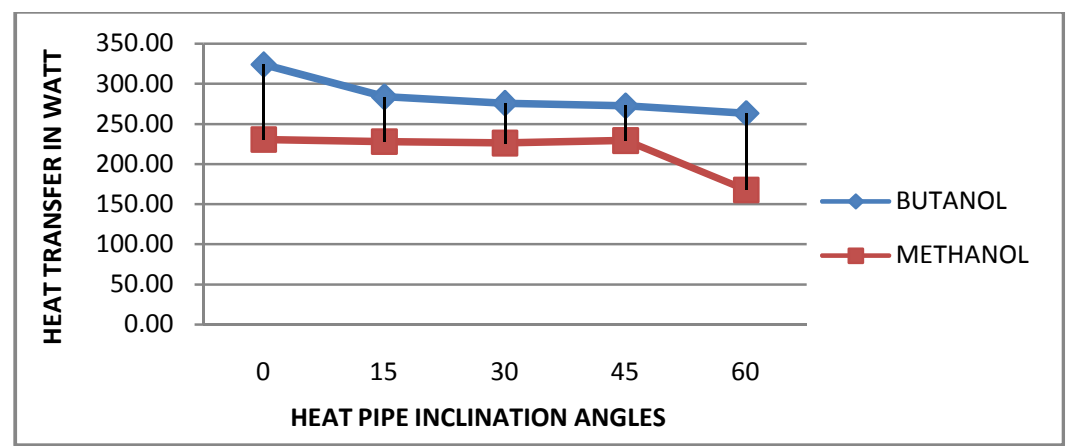

Figure 12: The practically calculated value of RHT for $61^{\circ} \mathrm{C}$ inlet temperature

Above study shows that RHT is influenced by slope as well as by inlet temperature of HPHEVC. It is noted that as tilt angle of HP increases from vertical axis $0^{\circ}$ to $15^{\circ}$ the RHT decreases and it starts increasing beyond $15^{\circ}$ tilt angle after that again start decreasing RHT from $45^{\circ}$ to $60^{\circ}$ tilt angles for all the inlet temperature of evap..

\section{CONCLUSIONS}

\subsection{The Co-efficient of Heat Transfer for HPHEVC is Found that:}

- The utmost value of co-efficient of convective heat transfer is $654 \mathrm{~W} / \mathrm{m}^{20} \mathrm{C}$ at $15^{0}$ tilt angle of $\mathrm{HP}$ at $61{ }^{0} \mathrm{C}$ inlet temperature of evaporator for methanol used as functioning fluid.

- The lowest value of co-efficient of convective heat transfer is $367.10 \mathrm{~W} / \mathrm{m}^{20} \mathrm{Cat} 60^{0}$ tilt angle of $\mathrm{HP}$ at $40{ }^{\circ} \mathrm{C}$ inlet temperature of evaporator for methanol used as functioning fluid.

- The utmost value of co-efficient of convective heat transfer is $874.32 \mathrm{~W} / \mathrm{m}^{20} \mathrm{C}$ at $15^{0}$ tilt angle of $\mathrm{HP}$ at $61{ }^{0} \mathrm{C}$ inlet temperature of evaporator for acetone or butanol used as functioning fluid.

- The lowest value of co-efficient of convective heat transfer is $439.90 \mathrm{~W} / \mathrm{m}^{20} \mathrm{C}$ at $60^{0}$ tilt angle of $\mathrm{HP}$ at $40{ }^{\circ} \mathrm{C}$ inlet temperature of evaporator for acetone or butanol used as working fluid.

- This study shows that butanol gives the good thermal execution as compare to methanol used as functioning fluid.

\subsection{The Heat Transport Rate for HPHEVC is Found that}

- The utmost value of heat transport rate is $230.31 \mathrm{~W}$ at $0^{0}$ tilt angle of $\mathrm{HP}$ at $61{ }^{0} \mathrm{C}$ inlet temperature of evaporator for methanol used as functioning fluid. 
- The lowest value of heat transport rate is $50.77 \mathrm{~W}$ at $60^{\circ}$ tilt angle of $\mathrm{HP}$ at $40{ }^{\circ} \mathrm{C}$ inlet temperature of evaporator for methanol used as functioning fluid.

- The utmost value of heat transport rate is $324.0 \mathrm{~W}$ at $0^{0}$ tilt angle of $\mathrm{HP}$ at $61{ }^{\circ} \mathrm{C}$ inlet temperature of evaporator for butanol used as functioning fluid.

- The lowest value of heat transport rate is $79.14 \mathrm{~W}$ at $60^{\circ}$ tilt angle of $\mathrm{HP}$ at $40{ }^{\circ} \mathrm{C}$ inlet temperature of evaporator for butanol used as functioning fluid.

- The lower experimental value of heat transport rate of HPHEVC may be due to higher thermal resistances.

- The thermal performance of HPHEVC when butanol used as functioning fluid is better than methanol used as functioning fluid.

\section{REFERENCES}

1. Silva, et al., Longitudinal vortex generator applied to heat transfer enhancement of a flat plate solar water heater, Applied Thermal Engineering 158 (2019) 113790 www.elsevier.com/locatelapthermeng

2. AfrozaNahar, et al., Numerical investigation on the effect of different parameters in enhancing heat transfer performance of photovoltaic thermal systems, Renewable Energy 132(2019) 284 e295 www.elsevier.com/locate/renene

3. Zhang, et al., A review of heat transfer enhancement techniques in plate heat exchangers Renewable and Sustainable Energy Reviews 101 (2019) 305-328 www.elsevier.com/locate/rser

4. Ivošević, et al., Thermal performances and their impact on design of bayonet-tube heat exchangers - single phase plug flow. Springer-Verlag GmbH Germany, 2019 https://doi.org/10.1007/s00231-019-02568-3

5. Afzal, et al., Steady and Transient State Analyses on Conjugate Laminar Forced Convection Heat Transfer, @ CIMNE, Spain 2019https://doi.org/10.1007/s11831-018-09303-x

6. Omar, Rodríguez. P. "Uv radiation by the Debye sphere interaction plasma-metal nanoparticles on the surface of plant tissue." International Journal of Applied Engineering Research and Development (IJAERD) ISSN (P): 2250-1584.

7. Keerti Sharma, et al., Natural convection heat transfers modelling by the cascaded thermal lattice Boltzmann method, IJTS 134 (2018) 552-564 www.elsevier.com/locatelijts

8. ENTA, Y., M. ARITA, and M. WADA. "DRY-OXIDATION RATE OF Si (100) SURFACE UP TO 2 nm-OXIDES THICKNESS. "International Journal of Applied and Natural Sciences (IJANS); 4. 6, Oct - Nov 2015; $51-56$

9. Acharya \&Sukanta K. Dash, Natural convection heat transfer from a hollow horizontal cylinder with external longitudinal fins: (2018) ISSN: 1040-7782 (Print) 1521-0634 http://www.tandfonline.com/loi/unht20

10. Obeidat, et al., Effect of cutoff radius, long range interaction and temperature controller on thermodynamic properties of fluids: PII:-S0378-4371(18)30001-3, https://doi.org/10.1016/j.physa.2018.01.001

11. E. Nee1, Numerical analysis of three dimensionalnatural convection in aclosed rectangular cavity under conditions of radiant heating and conjugate heat exchange, 01027 (2017) Smart Grids, DOI: 10.1051/matecconf/20179101027

12. Liu, et al., Heat Transfer Analysis of Passive Residual Heat Removal Heat Exchanger under Tube outside Boiling Condition Hindawi Volume 2017, Article ID 3497103, 10 pages https://doi.org/10.1155/2017/3497103

13. YUN, KYYOUL, et al. "NEW FABRICATION METHOD SUGGESTION OF THE MOTOR CORE WITH DISSIMILAR METAL BONDING METHOD."International Journal of Metallurgical, Materials and Chemical Engineering (IASET: IJMMCE) 
$\operatorname{ISSN}(P):$ Applied; 1. 3, Apr - May 2016; 1-8

14. Turgut, et al., Thermal design of spiral heat exchangers and heat pipesthrough global best algorithm, (C) Springer-Verlag Berlin Heidelberg 2016

15. Zhang, et al., Effects of the arrangement of triangle-winglet-pair vortexgenerators on heat transfer performance of the shell sideof a double-pipe heat exchanger enhanced by helical fins, () Springer-Verlag Berlin Heidelberg 2016 DOI 10.1007/s00231-016-1804-7

16. Shrivastava, Deepti, and M. M. Malik. "Enhancing efficiency of organic light emitting diodes through doping of cadmium sulphide nanocrystals." Int. J. Nanotechnol. Appl 4.1 (2014).

17. Hazbehian, et al., Experimental investigation of heat transfer augmentation inside double pipe heat exchanger equipped with reduced width twisted tapes inserts using polymeric nanofluid. Springer-Verlag Berlin Heidelberg 2016 DOI 10.1007/s00231$016-1764-y$

\section{NOMENCLATURE}

$\begin{array}{lll}\text { Symbol } & \text { Description } & \text { Unit } \\ \mathrm{A} & \text { Surface area of HP } & \mathrm{m}^{2} \\ \mathrm{C}_{\mathrm{p}} & \text { Specific heat } & \mathrm{J} /(\mathrm{kg}-\mathrm{K}) \\ \mathrm{h}_{\text {practical }} & \begin{array}{l}\text { Practical value of } \\ \text { CCHT }\end{array} & \mathrm{W} /\left(\mathrm{m}^{2}-\mathrm{K}\right) \\ \mathrm{k} & \begin{array}{l}\text { Thermal } \\ \text { conductivity }\end{array} & \mathrm{W} /(\mathrm{m}-\mathrm{k}) \\ & \begin{array}{l}\text { Practical value of } \\ \mathrm{Q}_{\text {practical }}\end{array} & \mathrm{W} \\ & \text { RHT }\end{array}$

\section{Subscript}

CCHT Coefficient of convective heat transfer

HP Heat pipe

HPHE Heat pipe heat exchanger

HPHEVC Heat pipe heat exchanger insulated with vacuum chamber

RHT Rate of heat transport 

